
\title{
Reseserch Suare \\ The Influence of by-Products From Brewery Spent Grain Hydrolysis on Lactic Acid Fermentation Efficiency
}

Magdalena Lech ( $\sim$ magdalena.lech@pwr.edu.pl)

Wroclaw University of Science and Technology: Politechnika Wroclawska https://orcid.org/0000-00031907-2429

\section{Research Article}

Keywords: Brewery spent grain, lactic acid, hydrolysis, fermentation

Posted Date: July 8th, 2021

DOl: https://doi.org/10.21203/rs.3.rs-680313/v1

License: (c) (1) This work is licensed under a Creative Commons Attribution 4.0 International License.

Read Full License 


\section{Abstract}

The brewery spent grain (BSG) is a lignocellulosic waste material produced in a huge amount around the world. Strict environmental protection law requires proper utilization. BSG can be transformed into easyfermentable carbohydrates as a result of hydrolysis. This may be a low-cost raw material for biotechnological fermentation. The literature provides a lot of information that hydrolysis of lignocellulose creates by-products which can be potentially noxious to bacteria cells employed in fermentation. This research examined the influence of most of these by-products: furfural, acetic, formic, gallic, and levuilnic acid, on the LA fermentation effectiveness. These components were introduced to Lactobacillus cultures in various concentrations. The rate of cell growth, glucose consumption, and lactic acid production were measured. This components affects in various extent on LA formation in the culture. In any case, there is a critical value of them harms the fermentation, due to the reduced ability of bacteria propagation. Lower concentrations of bio-catalyst lead to an LA production efficiency drop. The LA concentrations in flasks after one day of propagation with the $2.1[\mathrm{~g} / \mathrm{L}]$ of appropriate inhibitor drop app. [\%] $16(\mathrm{~F}), 22(\mathrm{GA}), 8(\mathrm{LevA}), 40(\mathrm{AA})$, and $100(\mathrm{FA})$ in comparison to the flask without any inhibitor.

\section{Key Points}

- The by-products of brewery spent grain hydrolysis can be noxius for lactic acid bacteria and decrease a lactic acid production from the hydrolysates

- The lower efficiency of lactic acid formation is a result of lower concentration of cells, mainly

- The most harmful properties has a formic acid - in this case, the lower concentration of lactic acid is a consequence of lower amount of cells and the reduced LA formation ability of cells, as well.

\section{Introduction}

Lignocellulosic wastes are the most promising substrates in bio-refineries (Kołtuniewicz and Dabkowska, 2016). This kind of biomass is the most abundant material around the world that can be used for any fermentation e.g. lactic acid, ethanol, or citric acid (Mussatto, Dragone and Roberto, 2006; Mussatto, 2014). It makes up all green biomass and a great amount of agro-industrial residues. The use of these materials does not entail depriving the foodstuff industry of its resources (so they are considered as feedstock used in the second generation (2G) bio-refineries).

Lignocellulose materials are available at a low price, rich in polysaccharides (Abdel-Hamid, Solbiati and Cann, 2013), and renewable. However, the cellulose and hemicellulose in the lignocellulose material are not directly available for bioconversion because of their association with lignin and lack of hydrolytic enzymes in the most common microorganisms used in fermentation (Abdel-Rahman, Tashiro and Sonomoto, 2011). The breakdown of polysaccharides into consumable sugars can start with breaking the lignocellulose structure, followed by hydrolysis to depolymerize lignocellulose to fermentative sugars (Komesu et al., 2017). 
The amounts of carbohydrate polymers and lignin obtained depends on the plant species. Also, the ratios between the sugars in a single plant may be different if we have in mind age, stage of growth, and other conditions. On the other hand, behind a fermentative carbohydrates formation, there are a lot of byproducts which may affect fermentation efficiency (Palmqvist and Hahn-Hägerdal, 2000; van der Pol et al., 2016) and sometimes even change the metabolic pathways of the cells employed in further fermentation (Zhang et al., 2016). The possible inhibitors of fermentation can be grouped into three major categories:

1. weak acids such as formic (from furfural degradation), levulinic (from HMF degradation), and acetic (formed by the deacetylation of hemicellulose);

2. furans as 5-hydroxymethylfurfural (HMF) and furfural (from pentose and hexose dehydration);

3. phenolic compounds (mainly from lignin breakdown) (Jönsson and Martín, 2016).

Brewery spent grain (BSG) is a major cellulosic by-product generated in large quantities in beer production (20 kg per $100 \mathrm{~L}$ of produced beer) (Mussatto, 2014). Nowadays, it is mainly utilized as cattle feed (Pejin et al., 2015), whereas it could be successfully utilized as a carbon source in biotechnological production, especially in fermentation.

As a typical cellulosic material, BSG can be hydrolyzed in many ways and the method determines the composition of hydrolysate and the concentration of fermentable sugars, e.g. glucose (Walker and Wilson, 1991; Morales-delaRosa, Campos-Martin and Fierro, 2014). Chemical hydrolysis is easy to perform and not expensive, especially in comparison to enzymatic breaking of cellulose and hemicellulose. The final product of chemical hydrolysis is very variable and contains a lot of hydrolysates other than glucose, e.g. aforementioned and potentially toxic compounds (Ajala et al., 2020). The disadvantages - such as higher costs and more complex conditions of the enzymatic process - can be compensated by predictable product composition (Yang et al., 2011).

In this research, there is a description of concept of using BSG hydrolysates application to lactic acid production. This acid has a wide range of industrial applications such as food additives (employed as an additive, acidulant, flavoring, and emulsifier) and in chemical synthesis (acrylic acid, lactate esters solvents, propylene glycol, etc. production). In the pharmaceutical industry, lactic acid is used in the production of cosmetics, formulating ointments, anti-acne solutions, humectants, and controlled-release drugs (Alves de Oliveira et al. 2018). The highest demand of this component is created in the biodegradable polymer industry for the PLA (polylactide) production. This renewable and biodegradable "plastic" is used for the production of food packaging and many types of utensils, which are replacing products made from raw petroleum (Datta et al. 1995). PLA can also be used in surgery, in the form of screws, pins, clamps, and boards (Alves de Oliveira et al. 2018). Due to its numerous applications (especially biodegradable polymers production), there is a great interest in finding alternative methods to produce it at the lowest cost possible and application of BSG hydrolysates develop this possibility 
Glucose formed in the pre-treatment process (depolymerization of lignocellulose) is easy-metabolized by LAB's, but the by-products formed simultaneously - furfural, weak acids (formic and acetic acid) and phenolic substances - can decrease fermentation efficiency (Palmqvist and Hahn-Hägerdal, 2000; van der Pol et al., 2016; Zhang et al., 2016). This research investigated the influence of the mentioned compounds on lactic acid fermentation yield. In the case of chemical hydrolysis of BSG, the composition of hydrolysates is dependent on applied conditions (concentration of acid, time of the process, or BSG/acid ratio) (Binder and Raines, 2010; Morales-delaRosa, Campos-Martin and Fierro, 2014). Hence the results can indicate the optimal conditions for BSG hydrolysis, which provides a product with allowable concentrations of toxic substances.

The main goal of this research was to determine the influence of the by-products of brewery spent hydrolysates on LA fermentation efficiency. These by-products hydrolysates include:

1. Furfural - a product of hexose dehydration;

2. Gallic acid (as a phenolic substance) - the product of lignin breakdown;

3. Formic acid - from furfural degradation;

4. Levulinic acid - from HMF degradation;

5. Acetic acid - from acetylation of hemicellulose (Jönsson and Martín, 2016)

\section{Materials And Methods}

To test the influence of the potentially poisoning components, we applied cultures of Lactobacillus rhamnosus with different concentrations. During culturing we measured the concentrations of substrate (glucose), product (lactic acid), and biomass, which provided information about the impact of the added inhibitor on the rate of cell growth, substrate (glucose) conversion, and productivity (LA formation).

\subsection{Culturing}

To $100[\mathrm{~mL}]$ of sterile medium (the composition of it presents table 1) an appropriate amount of potentially toxic component and then $1 \%(1[\mathrm{~mL}])$ of inoculum was introduced. The cultures were incubated at $38^{\circ} \mathrm{C}$ (Valik and Lipatkova, 2008) with shaking at $120 \mathrm{rpm}$ on a rotary shaker (IKA KS 4000, Germany). The samples were collected in triplication while the culture was being grown. In every part of the experiment (testing each inhibitor) a control culture - without the inhibitor - was always incubated.

Table 1 presents the composition of the medium (Lech, 2020). 


\begin{tabular}{|ll|}
\hline Component & Concentration $[\mathrm{g} / \mathrm{L}]$ \\
\hline Peptone & 0.5 \\
\hline Meat extract & 0.4 \\
\hline Yeast extract & 2.0 \\
\hline Glucose & 20.0 \\
\hline $\mathrm{CH}_{3} \mathrm{COONa} \cdot 3 \mathrm{H}_{2} \mathrm{O}$ & 8.3 \\
\hline $\mathrm{K}_{2} \mathrm{HPO}_{4}$ & 2 \\
\hline $\mathrm{C}_{3} \mathrm{H}_{4}(\mathrm{OH})(\mathrm{COONH})_{3}$ & 2 \\
\hline $\mathrm{MgSO}_{4} \cdot 7 \mathrm{H} 2 \mathrm{O}$ & 0.2 \\
\hline $\mathrm{MnSO}_{4} \cdot \mathrm{H} 2 \mathrm{O}$ & 0.04 \\
\hline
\end{tabular}

\subsection{Inoculum}

MRS (De Man, Rogosa and Sharpe, 1960), the medium dedicated to lactic acid fermentation, was prepared and sterilized at $121^{\circ} \mathrm{C}, 1$ bar per 20 minutes. A single colony of Lactobacillus rhamnosus (PCM 489, Polish Academy of Science, Poland) from a MRS plate (containing $2 \%$ agar powder (Sigma Aldrich, CAS: $9002-18-0$ ) was transferred into $100 \mathrm{~mL}$ of sterile MRS. The conical flask was incubated at $38^{\circ} \mathrm{C}$ for 24 hours and shaken at $120 \mathrm{rpm}$ on a rotary shaker (IKA KS 4000, Germany), which led to the formation of a high-density culture (app. $5 \mathrm{~g} / \mathrm{L}$ cells).

\subsection{Concentration of glucose}

Glucose concentration was determined with the commercially colorimetric enzymatic test (Biomaxima, Poland). The intensity of the color was measured spectrophotometrically at $500 \mathrm{~nm}$ with a standard curve:

$$
C_{\text {glucose }}\left[\frac{g}{L}\right]=2.703 * A_{500}
$$

The protocol of method - $10 \mathrm{uL}$ of the measured sample was added to $1 \mathrm{~mL}$ of analytical reagent (Biomaxima, Poland) and incubated for $5 \mathrm{~min}$ at $37^{\circ} \mathrm{C}$. After this time the absorbance at $500 \mathrm{~nm}$ was measured.

\subsection{The concentration of lactic acid}

The concentration of lactic acid was analyzed by HPLC (Waters, USA) under isocratic conditions using a Synergi $4 \mu \mathrm{m}$ Hydro-RP $80 \AA \AA$ column (Phenomenex, USA). Samples were first filtered through a $0.22 \mu \mathrm{m}$ 
syringe filter and then eluted with $20 \mathrm{mM} \mathrm{K}_{2} \mathrm{HPO}_{4} / \mathrm{H}_{3} \mathrm{PO}_{4}\left(\mathrm{pH} \mathrm{2.9)}\right.$ at $30^{\circ} \mathrm{C}$ for 10 minutes. The flow rate was $0.042 \mathrm{~L} \mathrm{~h}^{-1}$ and the peak absorbance was monitored at $205 \mathrm{~nm}$. Lactic acid (Sigma Aldrich, CAS: 7933 -4), formic acid (Poch, Poland, CAS:64186), and acetic acid (Sigma Aldrich, CAS: 64-19-7) were run as standards. Under these conditions, the retention time for lactic acid was $6.12 \mathrm{~min}$ and the concentration was calculated with the standard curve:

$$
C_{\text {lactic acid }}\left[\frac{g}{L}\right]=4.35 * 10^{-6} * A
$$

(where: $\mathrm{A}$ - area of peak $[\mu \mathrm{V} \cdot \mathrm{min}])$.

\subsection{Biomass concentration}

The biomass and lactose were evaluated spectrophotometrically (Hitachi, USA). The biomass content was measured at $550 \mathrm{~nm}$ from the standard curve based on the dry mass method:

$$
C_{\text {Lc.rhamnosus }}\left[\frac{g}{L}\right]=1.0123 * A_{550}
$$

\section{Results}

Inhibitors added to the cultures have a significant though varied impact on cells growth rate, glucose consumption, and LA production. Some of them are stronger than others and even a small amount of them slows down bacteria growth and metabolism.

\subsection{Influence of furfural}

Furfural was tested first. This aldehyde is present in BSG hydrolysate due to the reduction of xylose (which is a product of hemicellulose hydrolysis) (Mathew et al., 2018) and is formed in smaller amounts during BSG hydrolysis than other ingredients poisonous to fermentative bacteria e.g. acetic acid (Jönsson and Martín, 2016). To investigate the influence of this component on LAB metabolism, furfural in culture concentrations within a range of 0.1 to 2.7 (the concentration of furfural in the flasks increased every 0.2$)[\mathrm{g} / \mathrm{L}]$ were tested. This component was chosen as a furans representative to determine the impact of this type of hydrolysis by-product on lactic acid microbial production. Figure 1 presents the results of growth curves in each of the flasks with an increasing concentration of furfural. To improve the clarity of the graph only selected data was presented. The presence of the furfural in culture does not have a significant impact on the ability of cells growth.

However, in the flasks with higher concentrations of added inhibitor, an amount of utilized glucose is reduced. Hence, in the flask with more than $2.1[\mathrm{~g} / \mathrm{L}]$ of furfural, the amount of utilized glucose was reduced app. 12 \% (from 7.04 to 6.19 [g/L]). Further addition of furfural reduces this factor even more. 
The slight impact of furfural on the culture can be observed in the case of LA production. Despite the fact that bacteria consume glucose, their metabolic pathways change and the main product is formed to a lesser extent (Horváth et al., 2003). An amount of furfural lower than 0.3 [g/L] does not affect the amount of produced LA (Figure 3), whereas addiction $2.1[\mathrm{~g} / \mathrm{L}]$ results in an app. $16 \%$ reduction at formed LA (from 8.60 to 7.20 [g/L] after 24 hours of culturing). Further addition of furfural causes a corresponding decline in the amount of lactic acid.

\subsection{Influence of gallic and levulinic acid}

Gallic acid (GA) was selected as a phenolic compound representative (formed mainly from lignin breakdown) and levulinic acid (LevA) from 5-hydroxymethylfurfural as the next potential inhibitors in lactic acid fermentation. A series of experiments with GA and LevA were conducted in the same way as furfural experiments. The concentrations of GA and LevA in the L.rhamnosus cultures were from 0.1 to $2.7[\mathrm{~g} / \mathrm{L}]$.

The addition of gallic acid (GA) gave similar to furfural in culture results. The extra amount of this ingredient in the medium does not yield a higher concentration of cells, which is presented in Figure 4a. The concentration of LAB cells is moreover the same in every culture and the same effect occurs in cultures with levulinic acid addiction (Figure 4b)

It might seem that gallic and levulinic acid is not a potential inhibitor of lactic production. However, the same cells concentrations are not reflected in the same level of glucose consumption or lactic acid production. The concentration of LevA lower than $1.9[\mathrm{~g} / \mathrm{L}]$ does not have an impact on the amount of metabolized glucose, whereas 2.7 [g/L] of LevA results in an app. $25 \%$ reduction of used glucose (from $7.11[\mathrm{~g} / \mathrm{L}]$ in the flask without LevA to $5.33[\mathrm{~g} / \mathrm{L}]$ in the flask with $2.7[\mathrm{~g} / \mathrm{L}]$ of $\mathrm{LevA}$ ).

Galic acid has a stronger influence on glucose consumption rate in culture than ]linic acid. Even a small amount reduces the ability to metabolize glucose. Hence, $0.1[\mathrm{~g} / \mathrm{L}]$ of GA results in an app. $8 \%$ reduction of used glucose (from $7.15[\mathrm{~g} / \mathrm{L}]$ in the flask without GA to $6.58[\mathrm{~g} / \mathrm{L}]$ in the flask with $0.1[\mathrm{~g} / \mathrm{L}]$ of GA).

When the productivity of L.rhamnosus cells is considered, even a small amount of GA (e.g. 0.5 [g/L]) reduced the amount of LA app. 13\% (from 8.80 to 7.38 [g/L]). However, an increase in GA concentrations more does not have a strong effect (the amount of product is very similar and the decline is more slight).

Due to the less harmful impact of LevA on the glucose consumption-ability of cells a similar amount of produced lactic acid in cultures is observed (in comparison to the control flask). Only a higher concentration of LevA results in LA production decline.

\subsection{Influence of formic and acetic acid}

The last part of the research was the determination of the toxic impact of formic (formed after furfural degradation) and acetic acid (formed by the deacetylation of hemicellulose) on L.rhamnosus culture. For this purpose, the concentrations in the range of 0.1 to 2.7 [g/ $\mathrm{L}]$ for both acids were examined. 
The results show that the primary drawback is that formic acid has a more significant impact on lactic acid bacteria growth than acetic one. In fact, only $0.5[\mathrm{~g} / \mathrm{L}]$ of this acid in the medium results in a drop in cells concentration app. $26 \%$ (from $3.66[\mathrm{~g} / \mathrm{L}]$ to 2.70 [g/L]) after 24 hours of culturing. An additional amount of formic acid affected bacteria growth more drastically: e.g. 1.3 [g/L] lowered cell concentration in the medium to only $0.67[\mathrm{~g} / \mathrm{L}]$ after one day of culturing.

Acetic acid, in contrast to formic acid, is less harmful to cells, however still more than the previous inhibitor (furfural, gallic and levulinic acid). A 0.9 [g/L] addition of this acid to cells culture decreased their concentration to 2.63 [g/L], which is app. $86 \%$ of the total amount of cells in the control (medium without any inhibitor). Concentrations of AA lower than 0.5 [g/L] do not have a significant impact on cell multiplication.

The high susceptibility of cells to the negative effect of formic acid is reflected in the amount of utilized glucose (Figure 9) and produced lactic acid (Figure 10). This is quite predictable mainly because of the lower concentration of the cells (as a biocatalyst).

The main goal of BSG hydrolysis is an application of the hydrolysates for fermentation, hence the impact of BSG hydrolysate inhibitors on cells efficiency is the most important. As it is presented in Figure 10 formic acid has a more harmful impact on process efficiency (which is associated with glucose utilization and cell growth rate decline) than acetic one. Namely, $0.5[\mathrm{~g} / \mathrm{L}]$ of FA results in the reduction in product formation by about $16 \%$ (from 9.79 to 8.26 ), whereas $1.1[\mathrm{~g} / \mathrm{L}]$ of FA reduced drastically produced lactic acid to $2.23[\mathrm{~g} / \mathrm{L}]$ - more than $75 \%$.

In the case of AA, there is no strict amount of this component which results in a noticeable drop in LA production. This decline is almost linear, e.g. $1.1[\mathrm{~g} / \mathrm{L}]$ of AA results in $9.95[\mathrm{~g} / \mathrm{L}]$ of LA production, which consists app. $84 \%$ of control concentration.

\subsection{The overall impact on cells productivity}

The calculation of the drop in fermentation efficiency i.e. the amount of produced LA in every flask in reference to the amount of LA in the control (without inhibitor) flask after 24 hours of culturing enabled a comparison of the harmful effect of every inhibitor. Figure 11 presents these results.

Figure 11 shows that the concentration of every investigated compound above $1.0[\mathrm{~g} / \mathrm{L}]$ has an impact on LA productivity in various extent. FA is undoubtedly the most noxious to culture. Even a small amount $(0.2[\mathrm{~g} / \mathrm{L}])$ decreases process efficiency, whereas an increase in LevA concentrations affects culture to the smallest extent.

A question arises here. Is the drop in lactic acid concentrations a consequence of the lower concentrations of cells only (less bio-catalyst is simply equal to less product) or a result of the cells poisoning effect? The calculation of cell efficiency (for an entire process) showed that FA has the most damaging impact on cells in terms of their LA production ability. Figure 12 presents results where the 
efficiency of cells was calculated as a ratio of produced LA in reference to a number of cells after 24 hours of breeding.

The cells efficiency in LA production in the case of furfural, levulinic, gallic, and acetic acid presence decrease in moreover linear but not sharply. It means that the major reason for the lower LA concentrations is a lower concentration of the cells, which is quite intuitive. The situation is different in the case of formic acid, where the amount of produced lactic acid is smaller in relation to the number of cells, as well.

\section{Discussion}

The brewery spent grain is a waste material produced in huge amounts. In 2019 world beer production reached 1.19 billion hectolitres (statista.com), which means that the BSG yield is app. 200 billion $\mathrm{kg}$ yearly. This lignocellulosic material can be transformed into a carbohydrate-source through hydrolysis and then successfully used as a medium in diverse biotechnological eco-friendly and useful processes involving bacteria, fungi, or yeast.

Hydrolysis is a noncomplicated and low-cost degradation method of lignocellulose. Every hydrolysis especially chemical (Zhang et al., 2016) - yields by-products (besides desirable carbohydrates), such as furfural, acetic, formic, and gallic acid. They are potentially adverse to microorganisms used in biotechnological (e.g. fermentation) processes. This research verifies the impact of these components on some fermentative bacteria cells (Lactobacillus rhamnosus from lactic acid bacteria group).

The results showed that the detrimental effect of the mentioned by-products of hydrolysis varies. The most toxic effect is exhibited by formic acid. A smattering amount of fromic acid results in a significant drop in cell efficiency. Furfural, acetic, levulinic and formic acid also have a negative impact on cells, but the concentrations which reduce fermentation yield were slightly higher (greater cell tolerance of them). On the other hand, furfural, acetic, levulinic and gallic acid inhibit mainly growth whereas the activity of cells remains the same. The lower cells efficiency was noticed in cultures with formic acid, where cells have a minor ability of LA formation.

\section{Declarations}

The datasets generated during and/or analysed during the current study are available from the corresponding author on reasonable request.

\section{Declaration of Competing Interest}

The author declare that she have no known competing interests or personal relationships that could have appeared to influence the work reported in this paper.

\section{References}


Abdel-Hamid, A. M., Solbiati, J. O. and Cann, I. K. O. (2013) 'Insights into Lignin Degradation and its Potential Industrial Applications', in Advances in Applied Microbiology. Elsevier, pp. 1-28. doi: 10.1016/B978-0-12-407679-2.00001-6.

Abdel-Rahman, M. A., Tashiro, Y. and Sonomoto, K. (2011) 'Lactic acid production from lignocellulosederived sugars using lactic acid bacteria: Overview and limits', Journal of Biotechnology, 156(4), pp. 286301. doi: 10.1016/j.jbiotec.2011.06.017.

Ajala, E. O. et al. (2020) 'Lactic Acid Production from Lignocellulose - A Review of Major Challenges and Selected Solutions', ChemBioEng Reviews, 7(2), pp. 38-49. doi: 10.1002/cben.201900018.

Binder, J. B. and Raines, R. T. (2010) 'Fermentable sugars by chemical hydrolysis of biomass', Proceedings of the National Academy of Sciences of the United States of America, 107(10), pp. 45164521. doi: 10.1073/pnas.0912073107.

Horváth, I. S. et al. (2003) 'Effects of furfural on the respiratory metabolism of Saccharomyces cerevisiae in glucose-limited chemostats', Applied and Environmental Microbiology, 69(7), pp. 4076-4086. doi: 10.1128/AEM.69.7.4076-4086.2003.

Jönsson, L. J. and Martín, C. (2016) 'Pretreatment of lignocellulose: Formation of inhibitory by-products and strategies for minimizing their effects', Bioresource Technology. doi: 10.1016/j.biortech.2015.10.009.

Kottuniewicz, A. B. and Dabkowska, K. (2016) 'Biorefineries - factories of the future', Chemical and Process Engineering - Inzynieria Chemiczna i Procesowa, 37(1), pp. 109-119. doi: 10.1515/cpe-20160011.

Komesu, A. et al. (2017) 'Lactic acid production to purification: A review', BioResources, 12(2), pp. 43644383. doi: 10.15376/biores.12.2.4364-4383.

Lech, M. (2020) 'Optimisation of protein-free waste whey supplementation used for the industrial microbiological production of lactic acid', Biochemical Engineering Journal, 157(February), p. 107531. doi: 10.1016/j.bej.2020.107531.

De Man, J. C., Rogosa, M. and Sharpe, M. E. (1960) 'A medium used for the cultivation of Lactobacilli', The Journal of Applied Bacteriology, 23, pp. 130-135.

Mathew, A. K. et al. (2018) 'Lignocellulosic biorefinery wastes, or resources?', in Waste Biorefinery: Potential and Perspectives. Elsevier B.V., pp. 267-297. doi: 10.1016/B978-0-444-63992-9.00009-4.

Morales-delaRosa, S., Campos-Martin, J. M. and Fierro, J. L. G. (2014) 'Optimization of the process of chemical hydrolysis of cellulose to glucose', Cellulose, 21(4), pp. 2397-2407. doi: 10.1007/s10570-0140280-9. 
Mussatto, S. I. (2014) 'Brewer's spent grain: A valuable feedstock for industrial applications', Journal of the Science of Food and Agriculture, 94(7), pp. 1264-1275. doi: 10.1002/jsfa.6486.

Mussatto, S. I., Dragone, G. and Roberto, I. C. (2006) 'Brewers' spent grain: Generation, characteristics and potential applications', Journal of Cereal Science, 43(1), pp. 1-14. doi: 10.1016/j.jcs.2005.06.001.

Palmqvist, E. and Hahn-Hägerdal, B. (2000) 'Fermentation of lignocellulosic hydrolysates. II: Inhibitors and mechanisms of inhibition', Bioresource Technology, 74(1), pp. 25-33. doi: 10.1016/S09608524(99)00161-3.

Pejin, J. et al. (2015) 'The influence of calcium-carbonate and yeast extract addition on lactic acid fermentation of brewer's spent grain hydrolysate', Food Research International, 73, pp. 31-37. doi: 10.1016/j.foodres.2014.12.023.

van der Pol, E. C. et al. (2016) 'Identifying inhibitory effects of lignocellulosic by-products on growth of lactic acid producing micro-organisms using a rapid small-scale screening method', Bioresource Technology, 209, pp. 297-304. doi: 10.1016/j.biortech.2016.03.037.

Valik, L'. and Lipatkova, D. M. A. (2008) 'Characterization of the growth of Lactobacillus rhamnosus GG', Journal of food and nutrition research, 47(2), pp. 60-67.

Walker, L. P. and Wilson, D. B. (1991) 'Enzymatic hydrolysis of cellulose: An overview', Bioresource Technology, 36(1), pp. 3-14. doi: 10.1016/0960-8524(91)90095-2.

Yang, B. et al. (2011) 'Enzymatic hydrolysis of cellulosic biomass', Biofuels, 2(4), pp. 421-449. doi: 10.4155/bfs.11.116.

Zhang, L. et al. (2016) 'Impacts of lignocellulose-derived inhibitors on I-lactic acid fermentation by Rhizopus oryzae', Bioresource Technology, 203, pp. 173-180. doi: 10.1016/j.biortech.2015.12.014.

\section{Figures}


Inhibitory initial concentration $[\mathrm{g} / \mathrm{L}]$ :

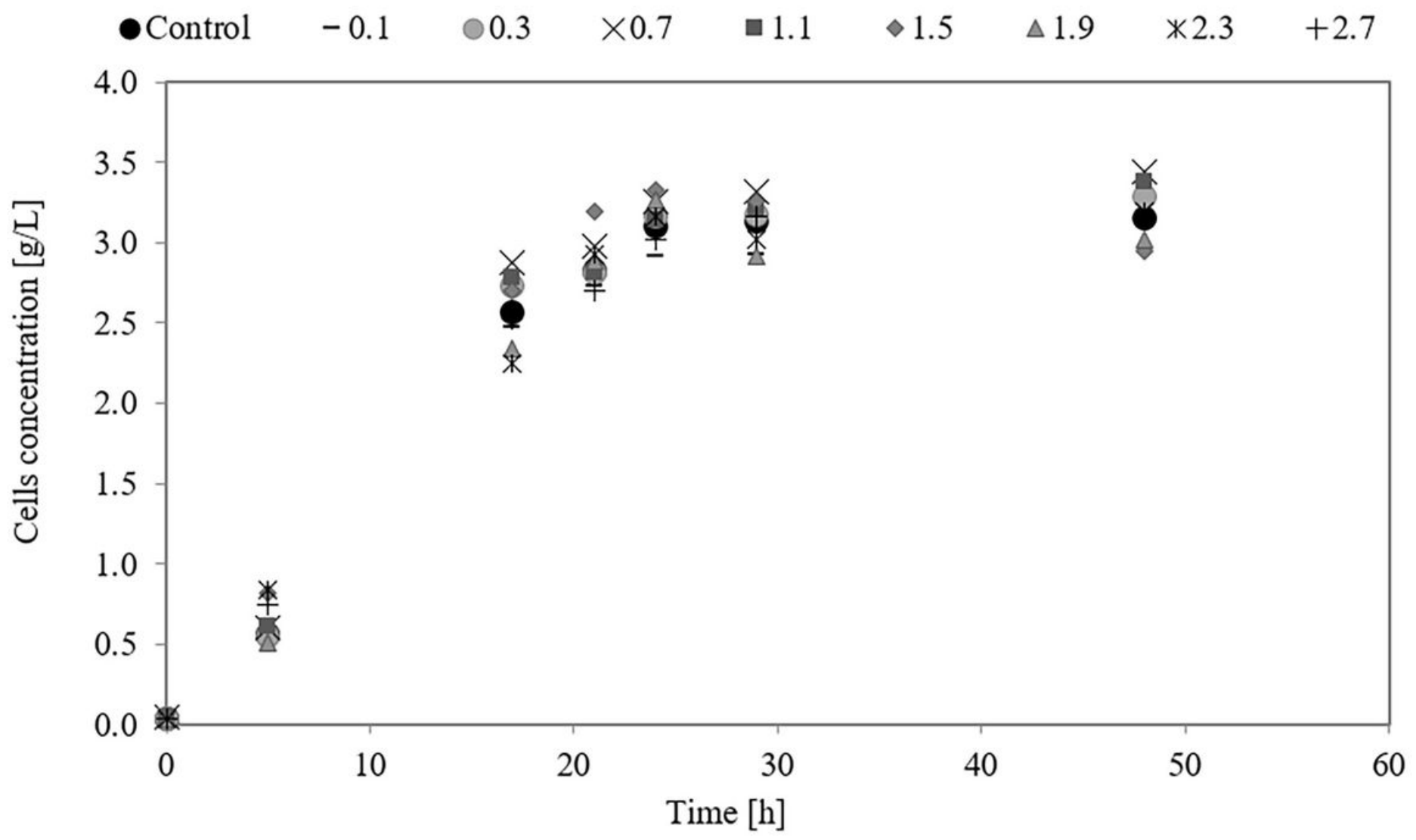

Figure 1

This component was chosen as a furans representative to determine the impact of this type of hydrolysis by-product on lactic acid microbial production. 
Inhibitory initial concentration $[\mathrm{g} / \mathrm{L}]$ :

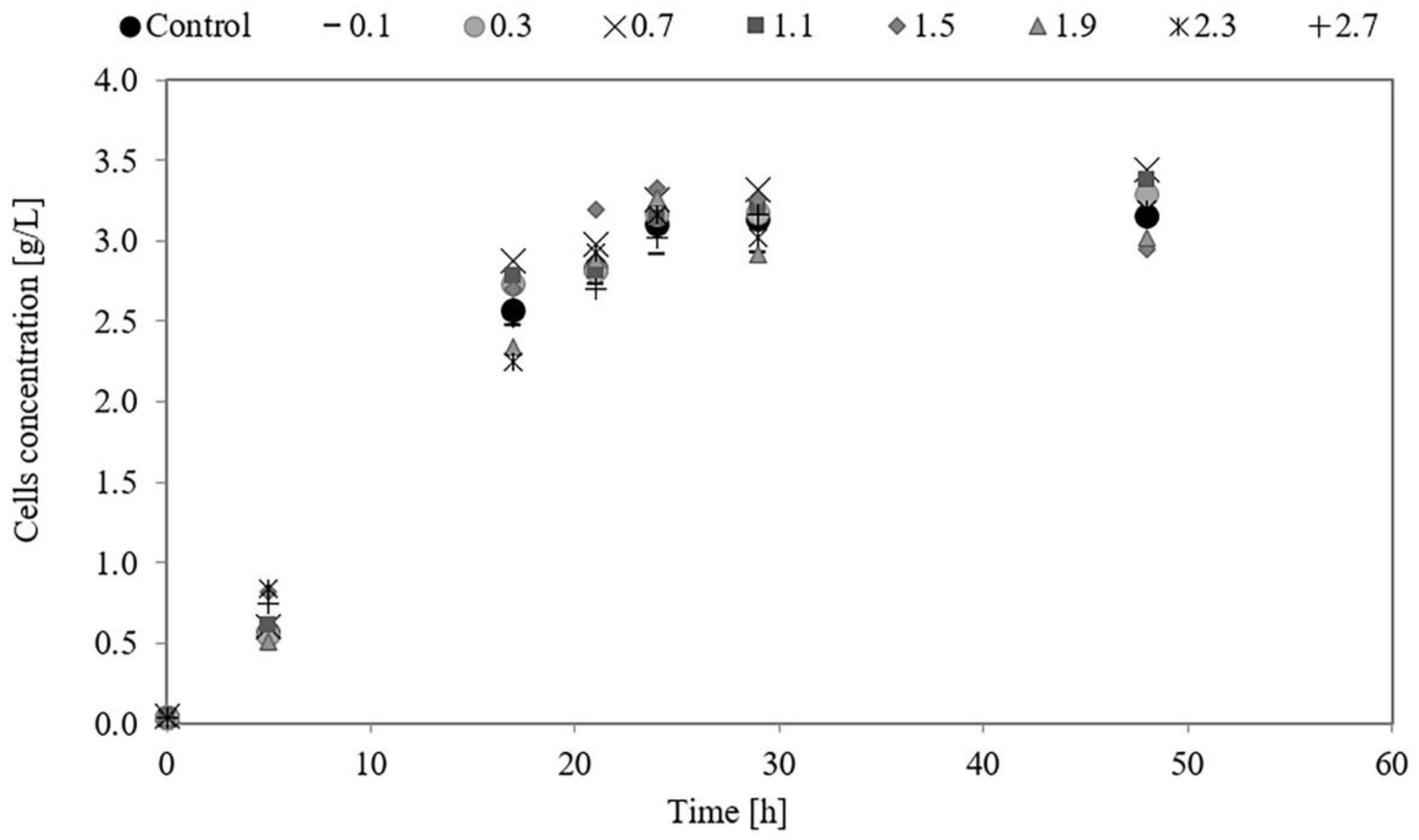

Figure 2

The presence of the furfural in culture does not have a significant impact on the ability of cells growth. 


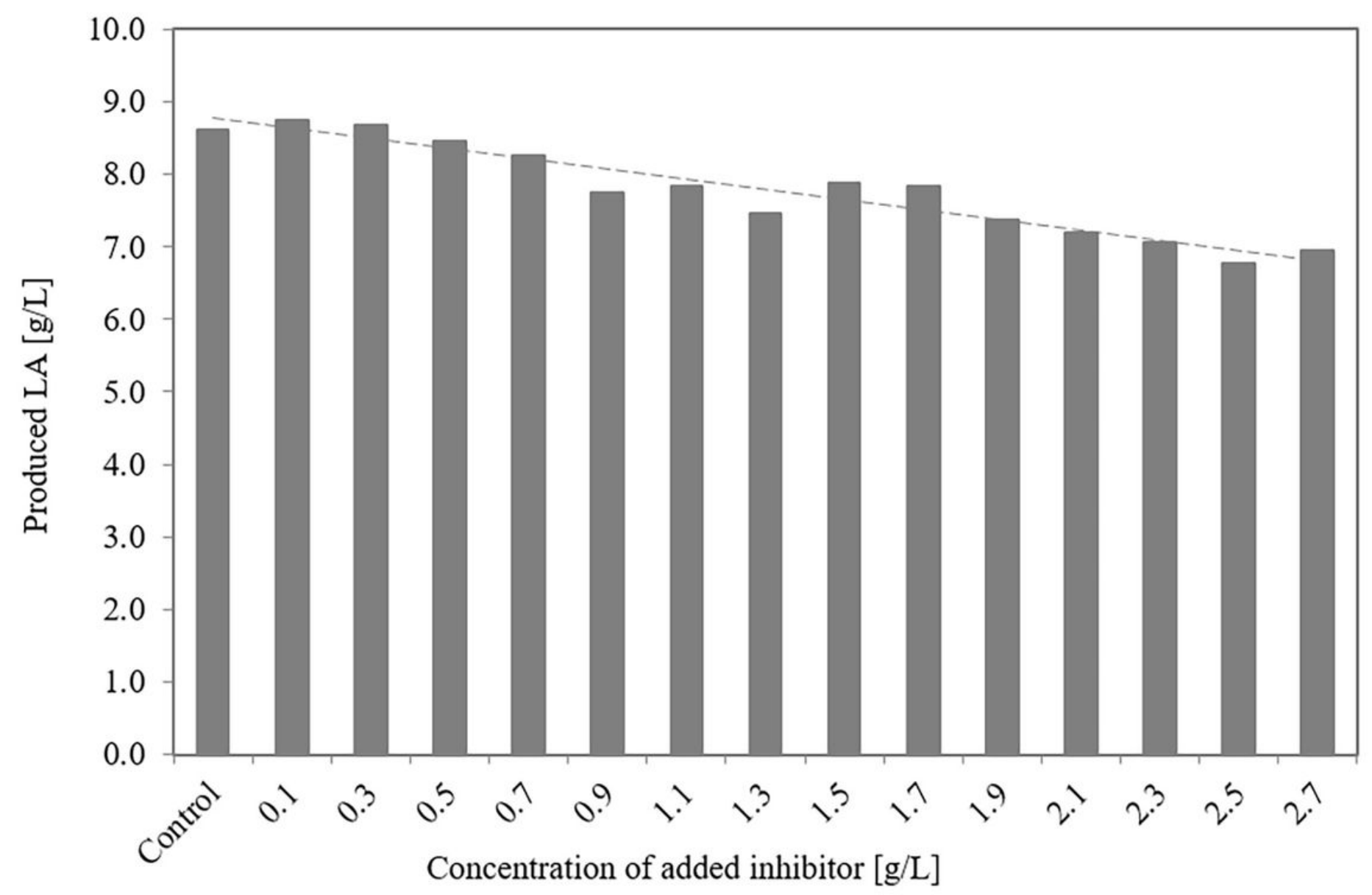

Figure 3

An amount of furfural lower than $0.3[\mathrm{~g} / \mathrm{L}]$ does not affect the amount of produced LA
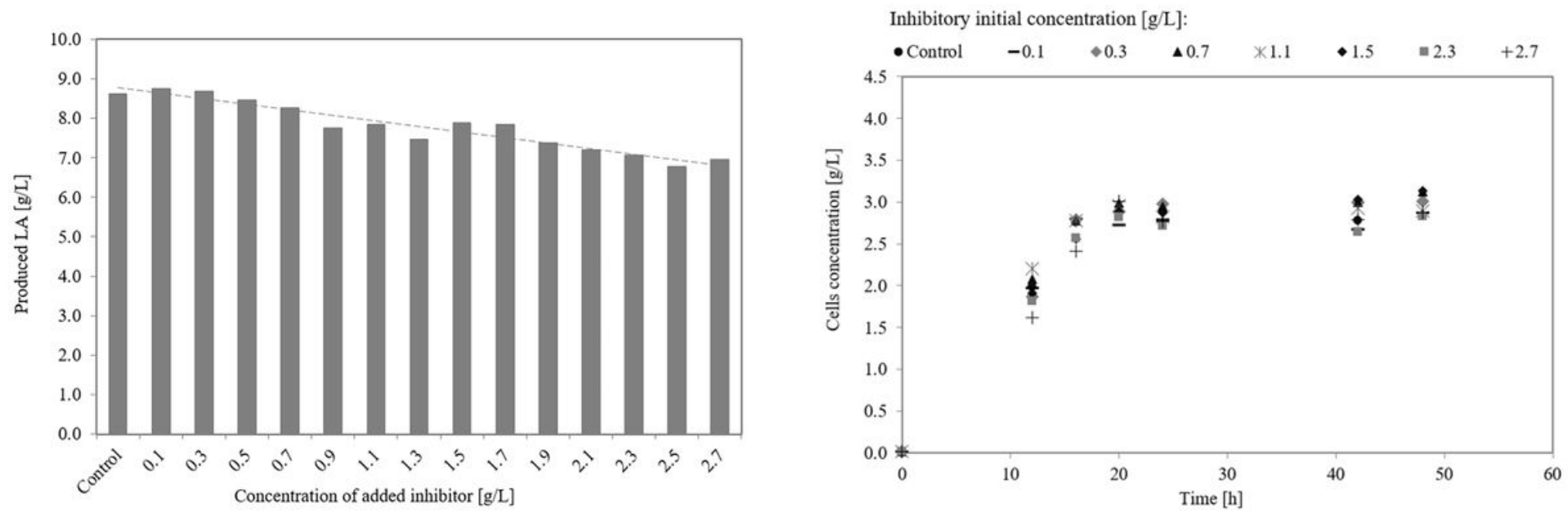

Figure 4

The addition of gallic acid (GA) gave similar to furfural in culture results. The extra amount of this ingredient in the medium does not yield a higher concentration of cells, which is presented. The 
concentration of LAB cells is moreover the same in every culture and the same effect occurs in cultures with levulinic acid addiction

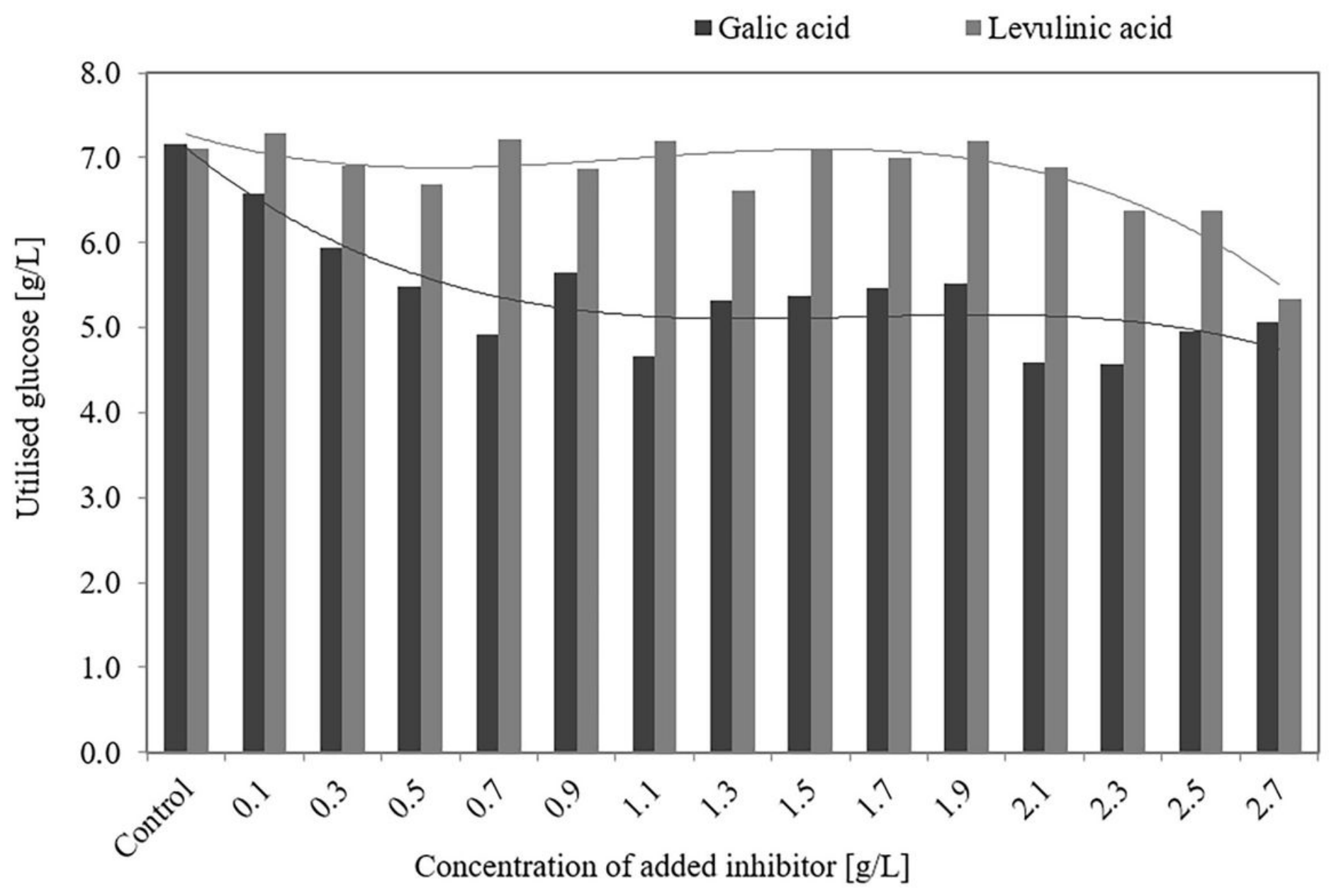

Figure 5

Galic acid has a stronger influence on glucose consumption rate in culture than ]linic acid. 


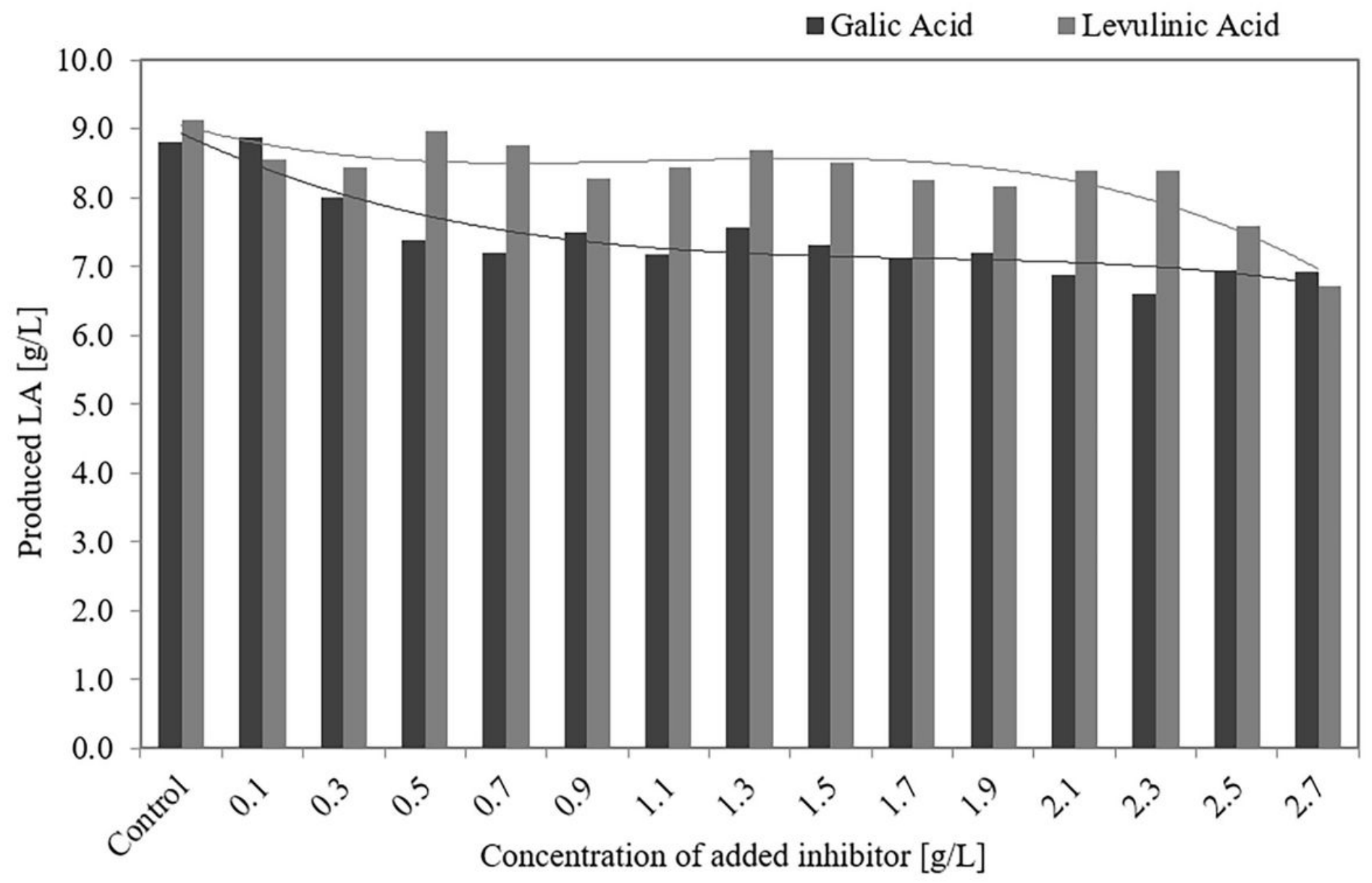

Figure 6

$8 \%$ reduction of used glucose (from $7.15[\mathrm{~g} / \mathrm{L}]$ in the flask without GA to $6.58[\mathrm{~g} / \mathrm{L}]$ in the flask with 0.1 $[\mathrm{g} / \mathrm{L}]$ of $\mathrm{GA})$. 


\section{Inhibitory initial concentration $[\mathrm{g} / \mathrm{L}]$ :}

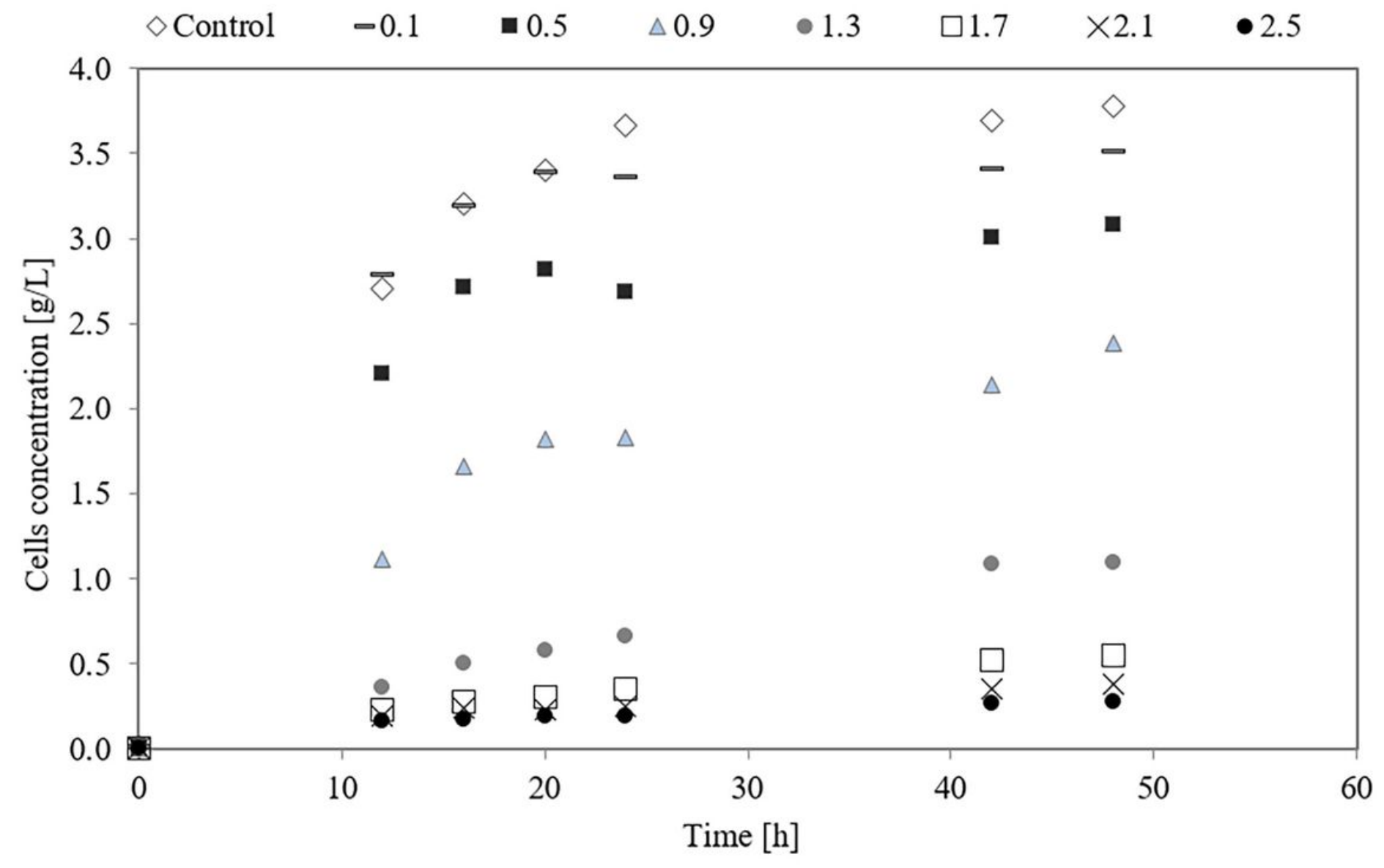

Figure 7

However, an increase in GA concentrations more does not have a strong effect (the amount of product is very similar and the decline is more slight). 
Inhibitory initial concentration $[\mathrm{g} / \mathrm{L}]$ :

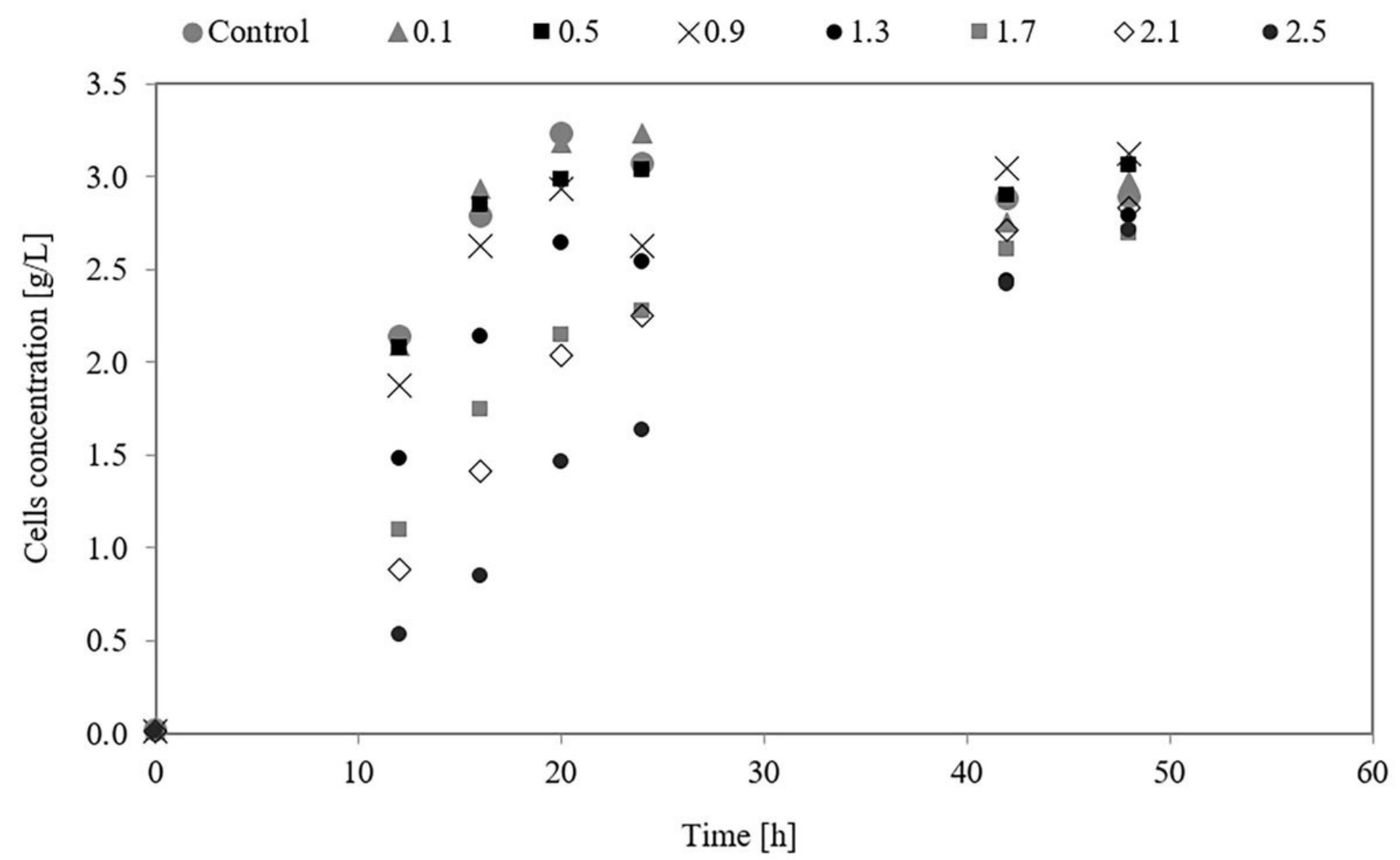

Figure 8

Due to the less harmful impact of LevA on the glucose consumption-ability of cells a similar amount of produced lactic acid in cultures is observed (in comparison to the control flask). Only a higher concentration of LevA results in LA production decline. 


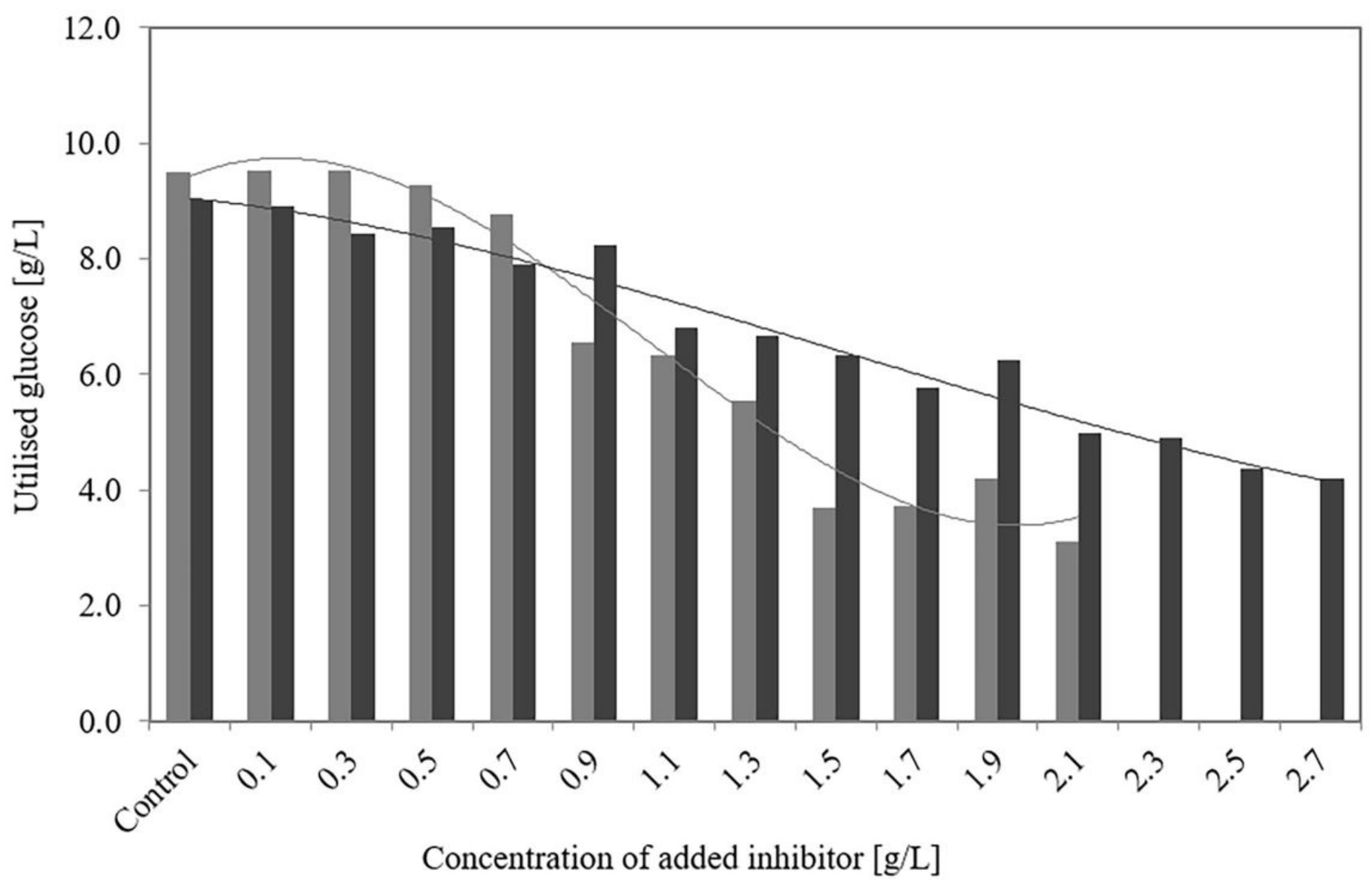

Figure 9

The high susceptibility of cells to the negative effect of formic acid is reflected in the amount of utilized glucose 


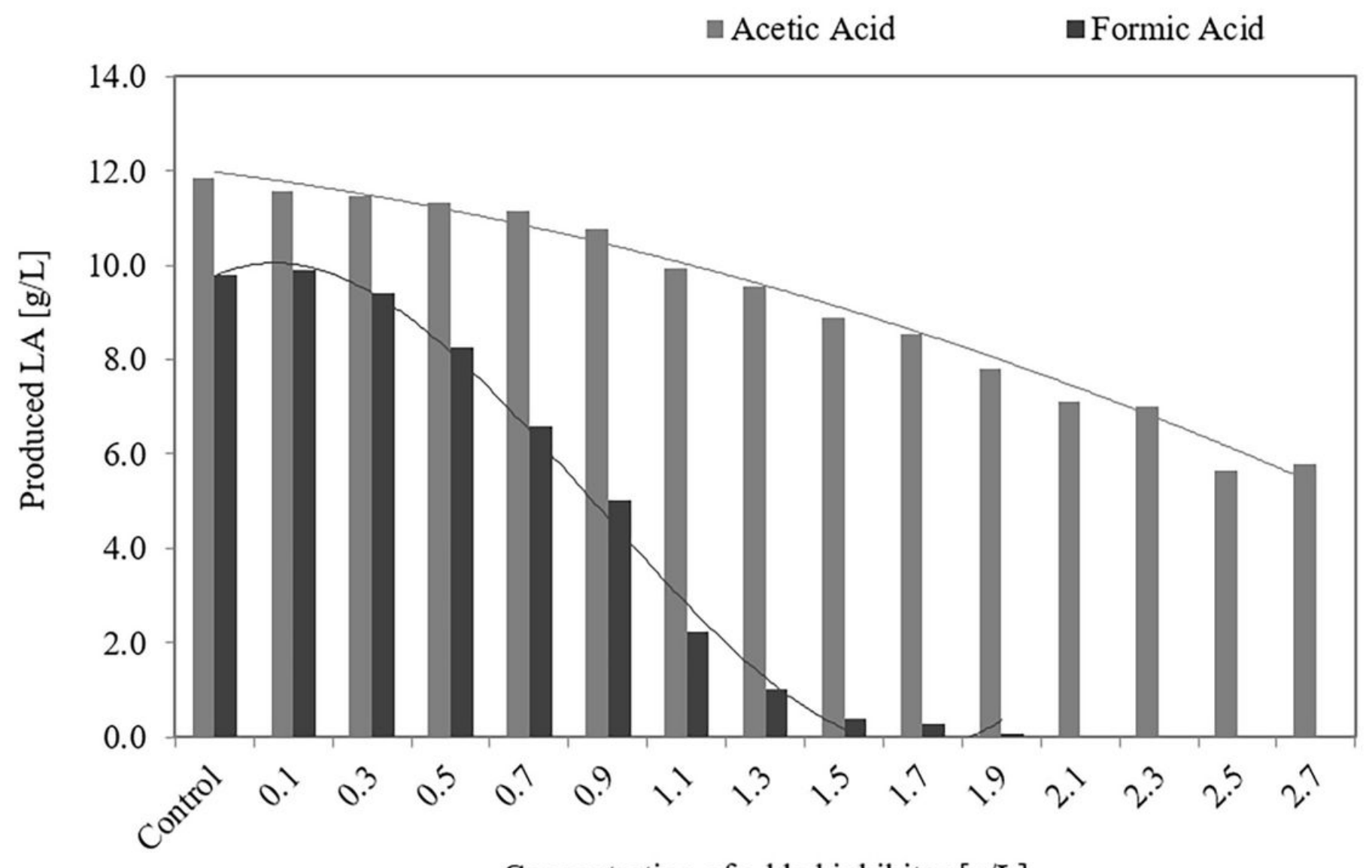

Concentration of added inhibitor $[\mathrm{g} / \mathrm{L}]$

Figure 10

This is quite predictable mainly because of the lower concentration of the cells (as a biocatalyst). 


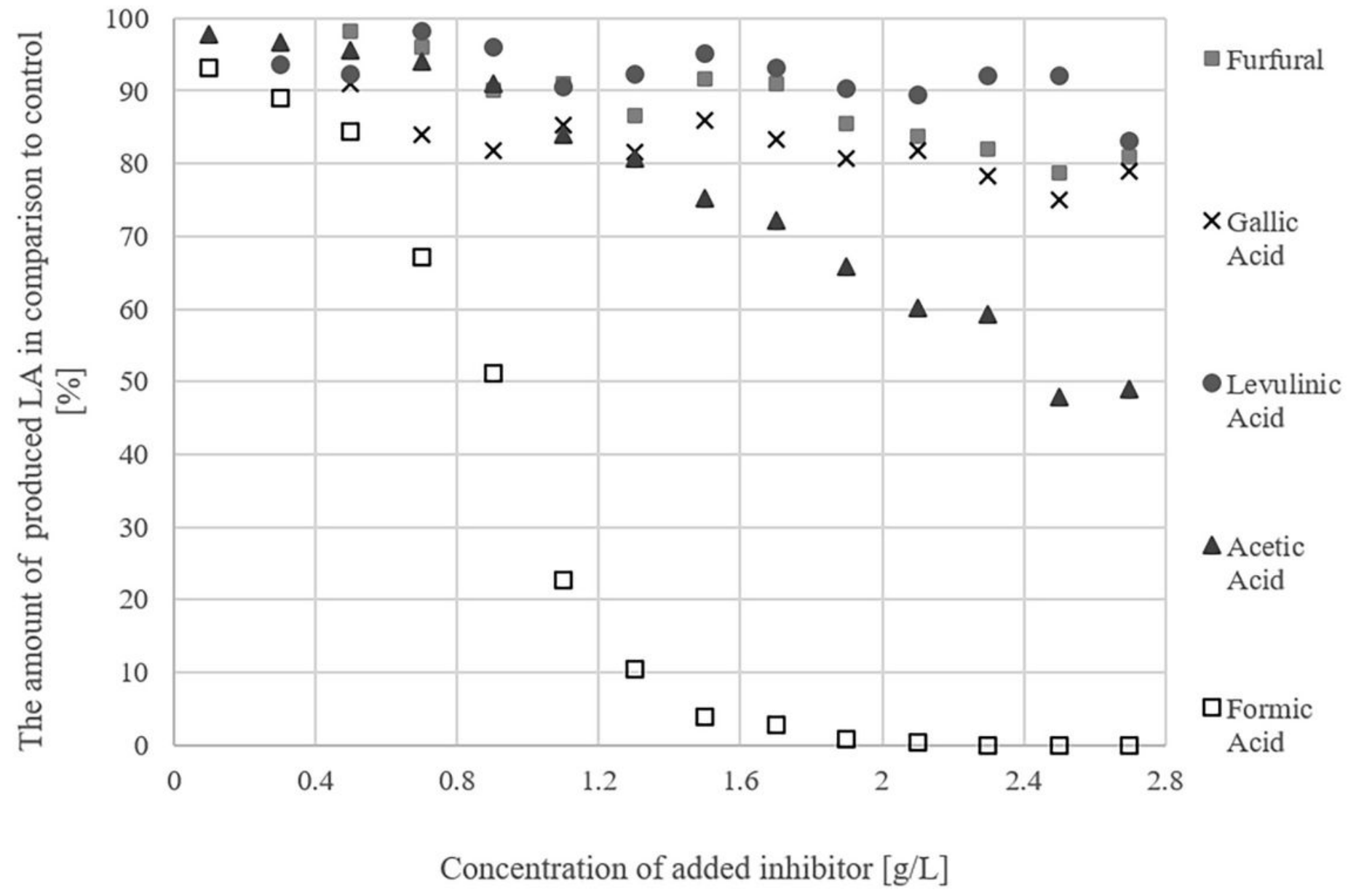

Figure 11

The calculation of the drop in fermentation efficiency i.e. the amount of produced LA in every flask in reference to the amount of LA in the control (without inhibitor) flask after 24 hours of culturing enabled a comparison of the harmful effect of every inhibitor. 


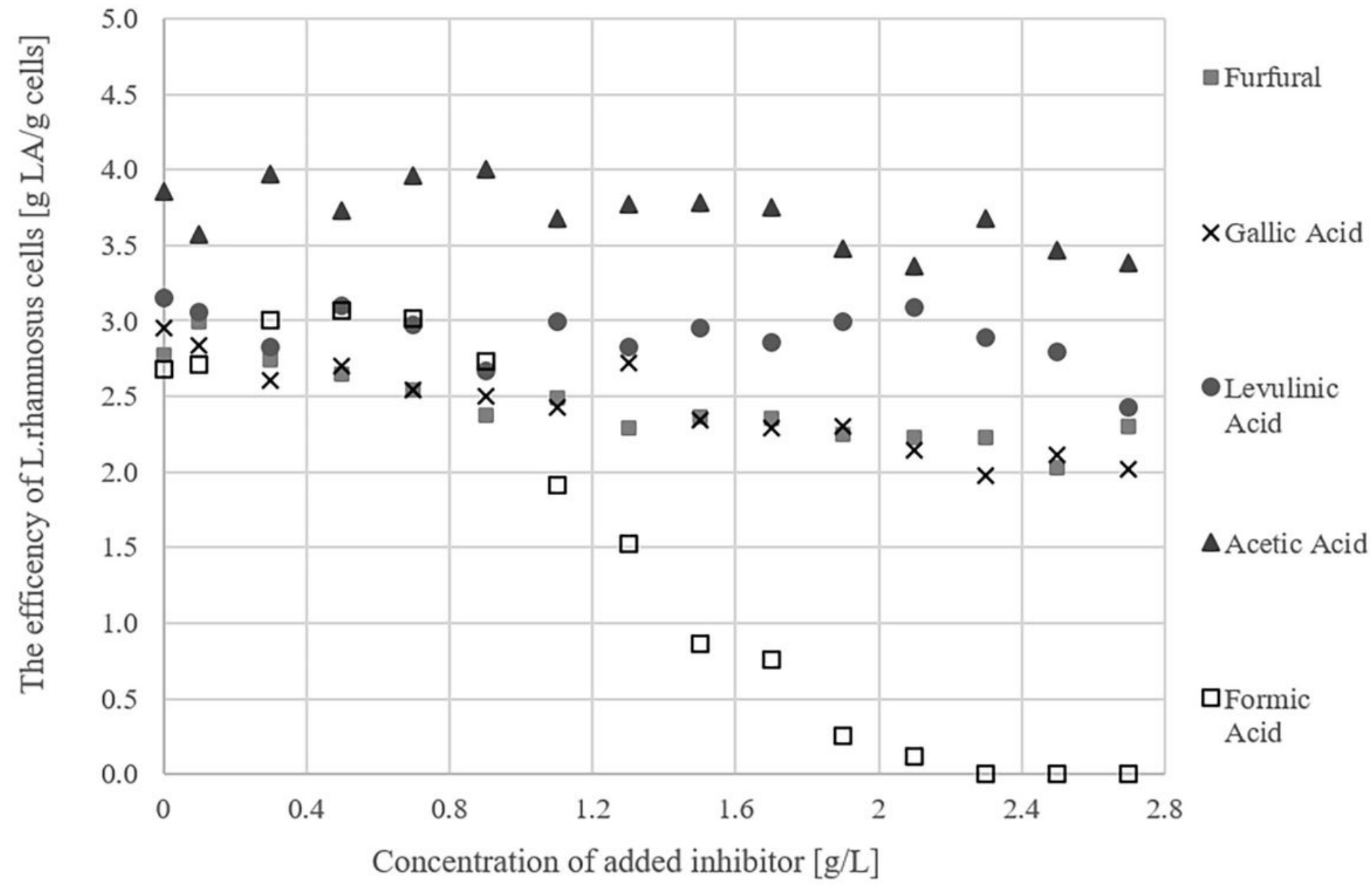

Figure 12

The calculation of cell efficiency (for an entire process) showed that FA has the most damaging impact on cells in terms of their LA production ability. 